\title{
LARP4B is an AU-rich sequence associated factor that promotes mRNA accumulation and translation
}

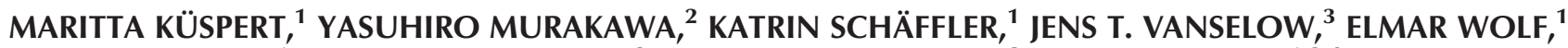 \\ STEFAN JURANEK, ${ }^{1}$ ANDREAS SCHLOSSER, ${ }^{3}$ MARKUS LANDTHALER, ${ }^{2}$ and UTZ FISCHER ${ }^{1,3,4}$ \\ ${ }^{1}$ Biozentrum Universität Würzburg, Am Hubland, D-97074 Würzburg, Germany \\ ${ }^{2}$ Max-Delbrück-Center for Molecular Medicine, D-13092 Berlin, Germany \\ ${ }^{3}$ Rudolf-Virchow-Zentrum für Experimentelle Biomedizin, Universität Würzburg, D-97080 Würzburg, Germany \\ ${ }^{4}$ Department of Radiation Medicine and Applied Sciences, University of California at San Diego, San Diego, California 92037, USA
}

\begin{abstract}
mRNAs are key molecules in gene expression and subject to diverse regulatory events. Regulation is accomplished by distinct sets of trans-acting factors that interact with mRNAs and form defined mRNA-protein complexes (mRNPs). The resulting "mRNP code" determines the fate of any given mRNA and thus controlling gene expression at the post-transcriptional level. The Larelated protein 4B (LARP4B) belongs to an evolutionarily conserved family of RNA-binding proteins characterized by the presence of a La-module implicated in direct RNA binding. Biochemical experiments have shown previously direct interactions of LARP4B with factors of the translation machinery. This finding along with the observation of an association with actively translating ribosomes suggested that LARP4B is a factor contributing to the mRNP code. To gain insight into the function of LARP4B in vivo we tested its mRNA association at the transcriptome level and its impact on the proteome. PAR-CLIP analyses allowed us to identify the in vivo RNA targets of LARP4B. We show that LARP4B binds to a distinct set of cellular mRNAs by contacting their 3' UTRs. Biocomputational analysis combined with in vitro binding assays identified the LARP4B-binding motif on mRNA targets. The reduction of cellular LARP4B levels leads to a marked destabilization of its mRNA targets and consequently their reduced translation. Our data identify LARP4B as a component of the mRNP code that influences the expression of its mRNA targets by affecting their stability.
\end{abstract}

Keywords: La-related proteins; translation; mRNA; mRNP code

\section{INTRODUCTION}

The maturation of mRNA and its commitment to translation are key events in gene expression. In eukaryotes, this process is initiated by the synthesis of precursor mRNA (pre-mRNA) by RNA polymerase II (RNAPII), followed by nuclear processing events and finally, nuclear export and transport to the site of translation in the cytoplasm. At all these stages mRNAs interact with trans-acting proteins to form mRNAprotein complexes (mRNPs). This "mRNP code" determines the fate of any given mRNA and thus is crucial for post-transcriptional gene regulation. mRNPs have been proposed to serve as post-transcriptional operons whose coordinated expression is determined by specific sets of RNA-binding proteins (RBPs) (Keene 2007). Such regulatory mechanisms are likely to be widespread, as recent studies have shown that the mRNA-bound proteome consists of a surprisingly large and diverse group of proteins, including enzymes not previously

Corresponding author: utz.fischer@biozentrum.uni-wuerzburg.de

Article published online ahead of print. Article and publication date are at http://www.rnajournal.org/cgi/doi/10.1261/rna.051441.115. set into context with RNA metabolism (Baltz et al. 2012; Castello et al. 2012).

The La-related protein (LARP) family comprises five major groups (Bousquet-Antonelli and Deragon 2009; Bayfield et al. 2010), whose common structural hallmark is the La module, a combination of the La motif and an adjacent classical RNA-recognition motif (RRM). Structural and biochemical studies (Alfano et al. 2003, 2004; Dong et al. 2004) on the genuine La protein (LARP3) revealed specific binding of the La module to 3' oligo-uridylic acid stretches (Stefano 1984; Wolin and Cedervall 2002; Teplova et al. 2006; KotikKogan et al. 2008). Accordingly, members of the LARP3 and LARP7 families associate predominantly with RNA polymerase III (RNAPIII) transcripts in vivo and influence their stability and/or maturation pathways (Sobel and Wolin 1999; Intine et al. 2000; Aigner et al. 2003; Chakshusmathi

(C) 2015 Küspert et al. This article is distributed exclusively by the RNA Society for the first 12 months after the full-issue publication date (see http://rnajournal.cshlp.org/site/misc/terms.xhtml). After 12 months, it is available under a Creative Commons License (Attribution-NonCommercial 4.0 International), as described at http://creativecommons.org/licenses/by$\mathrm{nc} / 4.0 \%$. 
et al. 2003; Aigner and Cech 2004; Prathapam et al. 2005; Stone et al. 2007; Copela et al. 2008; Krueger et al. 2008; Markert et al. 2008). While other LARP family members also contain La modules, recent evidence suggested that LARP1, LARP4, and LARP6 are associated with mRNAs rather than RNAPIII transcripts (Nykamp et al. 2008; Blagden et al. 2009; Wang et al. 2009; Weng et al. 2009; Burrows et al. 2010; Cai et al. 2010a; Schäffler et al. 2010; Zanin et al. 2010; Yang et al. 2011; Aoki et al. 2013; Mura et al. 2014; Tcherkezian et al. 2014). LARP6 has been shown to interact with a hairpin structure located in the $5^{\prime}$ untranslated region (UTR) of the mRNA encoding collagen. Binding resulted in the stimulation of collagen mRNA translation, thus identifying LARP6 as a positive translation factor (Cai et al. 2010a,b; Challa and Stefanovic 2011; Manojlovic and Stefanovic 2012; Wang and Stefanovic 2014). Whereas LARP6 likely targets only a small number of mRNAs carrying a specific secondary sequence motif in cis, LARP1 and LARP4 appear to influence translation in a broader sense. LARP1 has been shown to associate with many cytoplasmic mRNPs, primarily via interactions with translation factors including the poly(A)-binding protein PABPC1 but also via RNA sequences (Blagden et al. 2009; Burrows et al. 2010; Aoki et al. 2013; Mura et al. 2014; Tcherkezian et al. 2014). LARP1 has recently attracted major attention as it acts in the mTORC1 pathway to control the translation and stability of mRNAs containing the $5^{\prime}$ terminal oligopyrimidine tract (TOP) motif (Aoki et al. 2013; Tcherkezian et al. 2014). These TOP-mRNAs encode mostly factors of the translation machinery (i.e., ribosomal proteins and translation factors), thus putting the control of this class of mRNAs to the heart of cell growth and proliferation.

LARP4 is likewise part of many mRNPs and as in the case of LARP1 this association might be facilitated by direct interactions with cytosolic poly(A)-binding protein 1 (PABPC1) and ribosome-associated receptor for activated $\mathrm{C}$ kinase 1 (RACK1) (Yang et al. 2011). Although not yet proven experimentally, it is possible that LARP4 also directly contacts the mRNA as binding to poly(A) sequences has been shown in vitro (Yang et al. 2011). Binding of LARP4 to its mRNA targets increases their stability and thereby increases the expression of the encoded proteins (Yang et al. 2011).

We have recently provided evidence that LARP4B, a paralog of LARP4, acts as a positive factor of translation and interacts with the translation machinery via very similar protein-protein interactions (PABPC1, RACK1) as described for LARP4 and LARP1 (Angenstein et al. 2002; Bayfield et al. 2010; Burrows et al. 2010; Schäffler et al. 2010; Yang et al. 2011). Whether LARP4B also directly contacts specific mRNAs via defined sequence motifs and how it impacts on translation of its targets is currently unclear.

To gain insight into the function of LARP4B in vivo, we used systematic approaches to identify its mRNA association at the transcriptome level and its impact on the proteome. We identify LARP4B as a component of the mRNP code that binds to a large but distinct set of cellular mRNAs by contacting an AU-rich sequence element in their $3^{\prime}$ UTRs. Binding results in the stabilization of target mRNAs explaining the previously reported stimulatory effect of LARP4B on gene expression (Schäffler et al. 2010).

\section{RESULTS}

\section{PAR-CLIP identifies the LARP4B mRNA interactome}

As shown by structural analysis of the genuine La protein, the La motif and the adjacent RRM form together a defined " $\mathrm{La}$ module" that enables direct RNA binding (Bayfield et al. 2010). In the case of La, the targets are predominantly $3^{\prime}$ oligo-U stretches of RNAPIII transcripts. Since LARP4B contains a La module at its $\mathrm{N}$-terminus, we reasoned that it also binds RNA in vivo. To identify putative RNA targets in vivo, we performed a photoactivatable ribonucleoside-enhanced crosslinking and immunoprecipitation (PAR-CLIP) approach (Hafner et al. 2010). For this purpose, a stable HEK293 cell line expressing Flag/HA-tagged LARP4B under the control of an inducible promoter was used (Schäffler et al. 2010). This cell line expressed epitope-tagged LARP4B levels comparable to the endogenous protein (data not shown). The cell line was cultivated in medium containing 4-thiouridine (4SU) and the expression of Flag/HALARP4B was induced using tetracycline. After irradiation of the cell with UV-light (365 nm), Flag/HA-LARP4B was immunoprecipitated using anti-Flag coupled beads (data not shown). Crosslinked and co-immunoprecipitated RNAs were subsequently partially digested with RNase T1 and radioactively labeled with T4 polynucleotide kinase. The LARP4B/RNA complex was resolved by SDS-PAGE, blotted on a nitrocellulose membrane and visualized by autoradiography. As shown in Figure $1 \mathrm{~A}$, a $110 \mathrm{kDa}$ band was readily detectable in immunoprecipitates from the cell line cultivated in the presence of $4 \mathrm{SU}$ and irradiated with UV light (Fig. 1A, lane 1). This band, however, was absent in control immunoprecipitates of cell lysates where either UV treatment or 4SU was omitted (Fig. 1A, lanes 2 and 3, respectively). These results show that LARP4B can be directly crosslinked to 4SU-labeled RNA in vivo.

To identify the target transcripts, the LARP4B/RNA complex was eluted and digested with proteinase $\mathrm{K}$. After adapter ligation onto the isolated RNA and reverse transcription the obtained cDNA was amplified and identified by highthroughput sequencing using Illumina technology. Sequence reads of two biological replicates were extracted as described (Lebedeva et al. 2011) and mapped against the human genome. A total of 1.1 million reads mapped to the genome with up to one mismatch, insertion, or deletion. Both cDNA libraries contained a high fraction of reads with a characteristic T to $\mathrm{C}$ transition (48.7\%), indicative of a successful PAR-CLIP experiment (Fig. 1B). Initial analyses showed that the vast majority of reads mapped against genomic regions coding for mRNA. For downstream analyses combined 

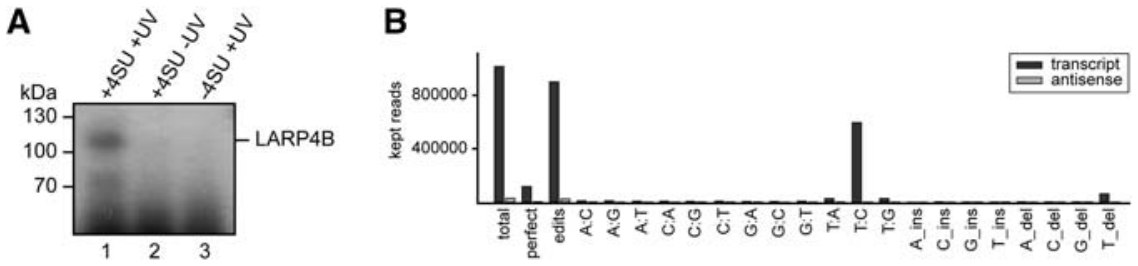

C
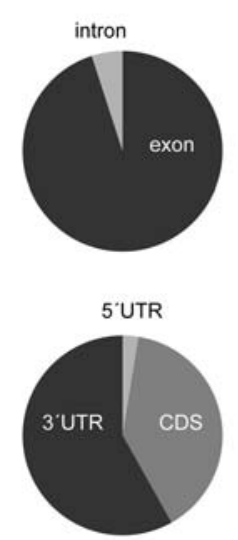

D
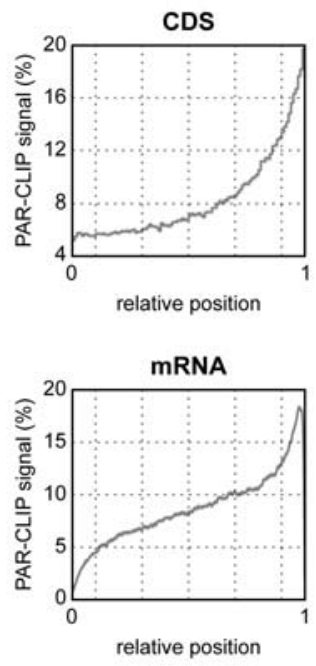

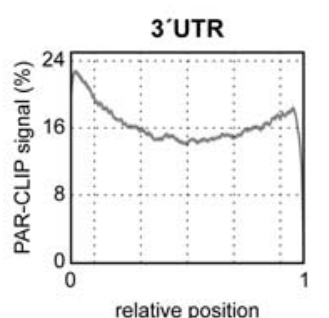

E

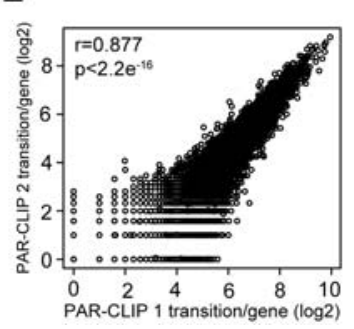

FIGURE 1. LARP4B PAR-CLIP experiment. (A) In vivo crosslinking of LARP4B and RNA. HEK293 cells stably expressing Flag/HA-tagged LARP4B were cultured in 4SU containing medium. After crosslinking LARP4B was immunoprecipitated, copurified RNA was partially digested and radioactively labeled at the $5^{\prime}$ end. The LARP4B-RNA complex was resolved by SDS-PAGE and bound RNA detected by autoradiography (lane 1). For control, UV-treatment (lane 2) or 4SU (lane 3) was omitted. (B) T:C transition in PAR-CLIP reads demonstrate efficient crosslinking of LARP4B and RNA. Kept reads were aligned to the human genome and the identified mismatches are depicted. (C) LARP4B interacts preferentially with $3^{\prime}$ UTRs. Alignment of binding clusters showed that LARP4B mainly binds to exonic regions. Here, the association with coding sequences and $3^{\prime}$ UTRs is favored. (D) LARP4B binding is enriched toward the end of the mRNA. The PARCLIP signal strongly increases toward the end of the CDS whereas it is almost evenly distributed throughout the $3^{\prime}$ UTR. This leads to an increase in LARP4B binding toward the end of the mRNA. (E) The LARP4B PAR-CLIP is highly reproducible. The number of T:C transitions per gene correlates significantly between the two PAR-CLIP replicates.

conservative clusters were built with the prerequisites that each library must contribute at least one read with a $\mathrm{T}$ to $\mathrm{C}$ transition event and only clusters that mapped to the coding strand were considered. A total number of 32,922 combined conservative clusters were obtained. Most clusters mapped to exonic regions $(95.0 \%)$, mostly to $3^{\prime}$ UTRs $(58.1 \%)$ but less often to $5^{\prime}$ UTRs $(2.6 \%)$ (Fig. 1C). This indicates that LARP4B binds to mature mRNA, which is in agreement with the previous finding that LARP4B is mostly cytoplasmic and hence unlikely to be in contact with nuclear pre-mRNA. A closer analysis of the genomic clusters revealed that LARP4B binding is enriched toward the $3^{\prime}$ end of the CDS while it is almost evenly distributed throughout the $3^{\prime}$ UTR (Fig. 1D). These clusters provided us with a list of 7906 candidate mRNA targets of LARP4B (Supplemental Table ST2) that were ranked according to the number of their $\mathrm{T}$ to $\mathrm{C}$ transitions (Lebedeva et al. 2011). The number of $\mathrm{T}$ to $\mathrm{C}$ transition per gene was compared between the two PAR-CLIP cDNA li-

braries and exhibited a significant correlation $(r=0.877)$ confirming good reproducibility between the two replicate experiments (Fig. 1E).

\section{Confirmation of candidate target mRNAs by RIP-PCR}

The data above provided a comprehensive set of mRNA targets that can be crosslinked to LARP4B by PAR-CLIP. To validate these targets by an independent method, we used RNA immunoprecipitation followed by RT-PCR analysis (RIP-PCRs). For this purpose, Flag/ HA-LARP4B was immunoprecipitated from cell extracts of control cells and cells overexpressing LARP4B using anti-Flag antibodies. Co-precipitated RNA was isolated and reverse transcribed using oligo (dT) primers. Selected LARP4B targets and nontargets were detected by PCR amplification using gene specific primers. As shown in Figure 2A, LARP4B interacted specifically with mRNAs that were identified by PAR-CLIP as candidate target mRNAs with high $\mathrm{T}$ to $\mathrm{C}$ transition events (Fig. 2A, lane 2). In contrast, mRNAs not identified in the PAR-CLIP analysis or considered to be weak targets based on their low number of $\mathrm{T}$ to $\mathrm{C}$ transitions were not detectable in the LARP4B immunoprecipitation (Fig. 2A, lane 2). Lastly, we wished to rule out that overexpression of LARP4B affects the pattern of RNA binding. For this we used extracts from HEK293 cells not expressing exogenous LARP4B and performed RIP-PCR studies on selected mRNAs co-immunoprecipitated with a LARP4B-specific antiserum (Fig. 2B, lane 2, see also bottom panel). To control for specificity an immunoprecipitation using pre-immune serum was performed (Fig. 2B, lane 3). In agreement with the data shown above, LARP4B was found to interact with those mRNAs that were identified as targets in the PAR-CLIP assay. However, an interaction with a nontarget mRNA (RCOR1) was not observed, further confirming the specific interaction of LARP4B with target mRNAs. These findings validate the PAR-CLIP data and confirm the interaction of LARP4B with a specific set of mRNAs.

\section{LARP4B associates with $A U$-rich sequences}

After demonstrating direct binding of LARP4B to mRNA, we asked next whether it recognizes specific RNA sequences in cis. Alternatively, binding to mRNA targets might occur 


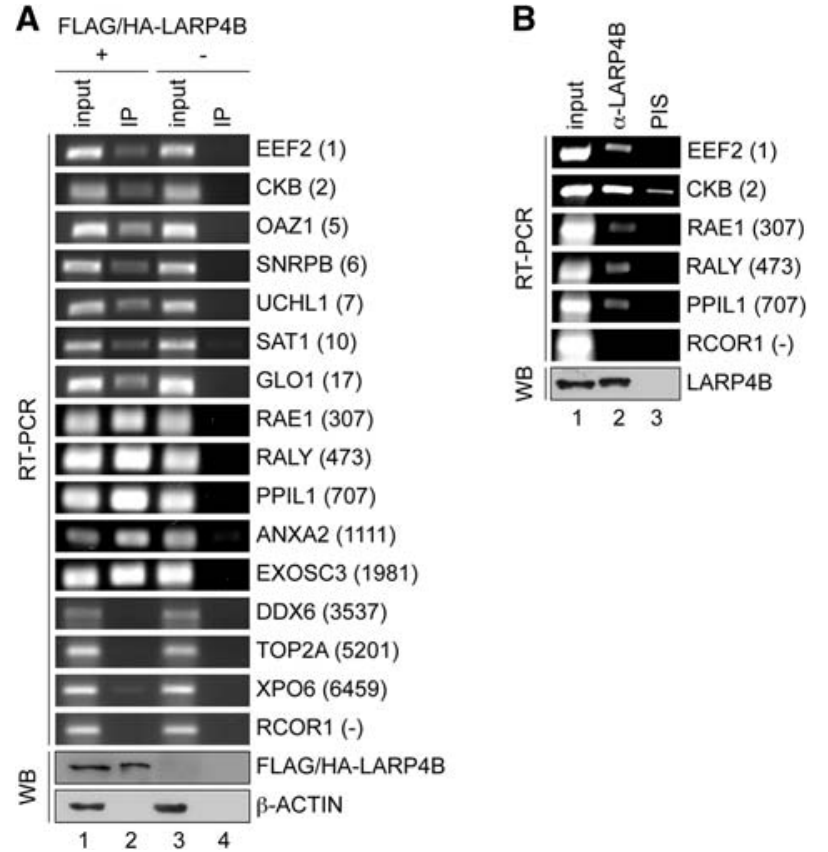

FIGURE 2. Validation of LARP4B target mRNAs. (A) Flag/HALARP4B was immunoprecipitated from cell extract of LARP4B overexpressing HEK293 cells using anti-Flag antibodies (lane 2). To control for specificity a cell line not overexpressing LARP4B was used (lane 4). Copurified RNA was isolated and analyzed by RT-PCR. mRNAs ranked high in the PAR-CLIP list could be confirmed as LARP4B targets while low ranked targets and nontargets could not be copurified. Western blot analysis demonstrates the efficiency of the LARP4B immunoprecipitation. (B) Endogenous LARP4B specifically interacts with target mRNAs. For immunoprecipitation of endogenous LARP4B an antiLARP4B antibody was used (lane 2). A control immunoprecipitation was performed with pre-immune serum (PIS, lane 3). Endogenous LARP4B interacted with target mRNAs while the control RNA, RCOR1 mRNA, was not co-immunoprecipitated.

in a sequence-independent manner by context-specific recruitment. The latter model appeared feasible as binding of LARP4B to PABPC1 and RACK1 had been reported (Angenstein et al. 2002; Schäffler et al. 2010).

To identify a potential LARP4B-binding motif, we counted the frequency of 7 mers in $41 \mathrm{nt}$ windows centered around the crosslink sites of the top $10003^{\prime}$ UTR-binding clusters as defined by $\mathrm{T}$ to $\mathrm{C}$ transitions. The vast majority of the 20 most abundant sequences are adenosine- and/or uridine-rich, indicating a preference of LARP4B for AU-rich sequences (Fig. 3A). To validate this finding experimentally in vitro binding assays were performed. For these studies recombinant LARP4B was expressed in Escherichia coli (Fig. 3B). As RNA probe for binding studies we chose a sequence derived from the LARP4B-binding site to the $3^{\prime}$ UTR of CKB mRNA (Fig. 3C). It encompasses the A/U-rich sequence centered around the putative binding site of LARP4B as identified by the $\mathrm{T}$ to $\mathrm{C}$ transition location.

${ }^{32} \mathrm{P}$-labeled RNA was incubated with increasing amounts of recombinant LARP4B and analyzed by native gel electrophoresis. As shown in Figure 3D LARP4B bound to the CKB se- quence with a dissociation constant of $\sim 200 \mathrm{nM}$ (Fig. 3E). Of note, binding was strictly dependent on uridines as a deletion mutant missing the U-stretch (termed CKB del) failed to bind (Fig. 3E,F). Furthermore, only marginal binding of LARP4B was observed to a sequence found in the $3^{\prime}$ UTR of a nontarget (TOP3B) and lacking the characteristic AU-rich element (Fig. 3C,G). However, a 11-nt long U-stretch derived from the CKB message was not sufficient for binding (data not shown). These experimental data together with the biocomputational predictions define sequences containing an AUrich element flanked by additional sequences without discernable motifs as the binding site of LARP4B.

\section{LARP4B stabilizes the target mRNAs}

The data above identify LARP4B as an mRNP component that targets mRNAs via recognition of specific sequence elements predominantly found in their $3^{\prime}$ UTRs. This suggested that LARP4B directly influences the expression of bound mRNAs at the post-transcriptional level and the knowledge about the interactome of LARP4B mRNAs enabled us to address this possibility. The cytoplasmic localization and the likely exclusive incorporation into mature (i.e., "late") mRNPs suggested that LARP4B might have a role in translation or stability of mRNAs.

The potential effect of LARP4B on mRNA translation was assayed first by comparison of polysome gradient profiles in extracts derived from control and LARP4B knockdown cells. We reasoned that in the case of a direct stimulatory effect of LARP4B on translation its target mRNAs would shift from polysomal into subpolysomal fractions upon LARP4B depletion. Total RNA from individual gradient fractions was isolated and the sedimentation pattern of selected target and nontarget mRNAs was analyzed by RT-PCR. As shown in Figure 4A, LARP4B deprivation had no measurable effect on the sedimentation pattern of both target and nontarget mRNAs and hence on their association with the translation machinery (Fig. 4A). This finding, although not excluding a role of $L A R P 4 B$ on translation, pointed toward a function of LARP4B in regulation of mRNA stability. To assess this possibility the effect of LARP4B on mRNA stability was measured at the transcriptome level. For this purpose mRNAs extracted from control and LARP4B-depleted cells were analyzed by RNA-seq allowing the determination of the changes of the mRNA levels. The comparison of the changes in expression levels of the top 1000 LARP4B target mRNAs with the remaining nontarget $m R N A s$ showed a significant reduction of the target mRNAs (Fig. 4B). To confirm this observation by an independent approach qPCRs of selected mRNAs isolated from LARP4B knockdown and control cells were performed and their relative expression determined. The target mRNAs RAE1, PPIL1, and EXOSC3 showed a decrease in expression levels of $\sim 40 \%-50 \%$ when LARP4B was depleted (Fig. 4C). In contrast, the expression levels of the nontarget mRNAs PRKAA1, XPO6, and TFRC showed only minor 


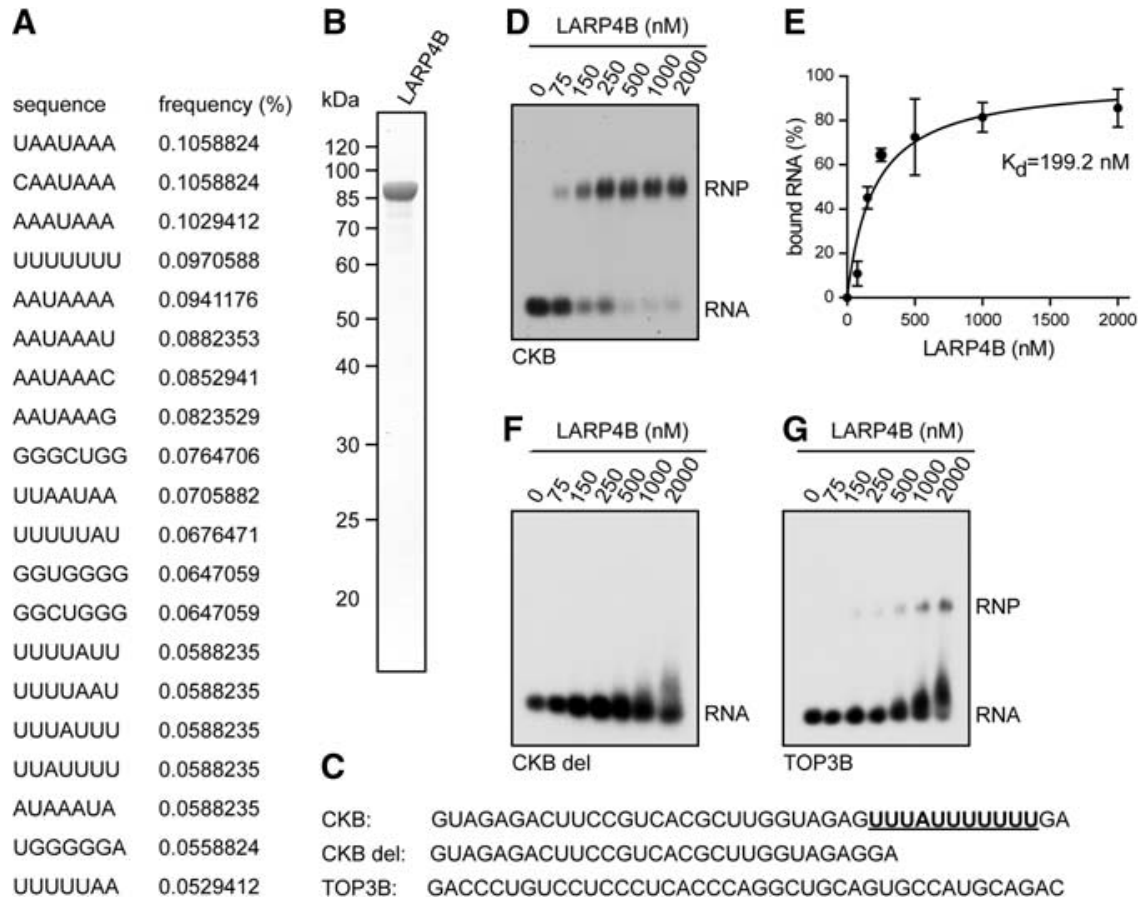

FIGURE 3. LARP4B associates with AU-rich sequences. (A) LARP4B-binding motif search. A binding motif search was performed as 7 mer frequency count in 41-nt windows centered around the crosslinked centered region of the top 1000 binding clusters in $3^{\prime}$ UTRs. The 20 most abundant sequences are depicted. $(B)$ Recombinant LARP4B expressed in E. coli was used for in vitro binding studies. $(C)$ RNA sequences for in vitro binding studies. An RNA sequence of the CKB $3^{\prime}$ UTR was used as LARP4B target sequence. This sequence contains an U-rich region. To assay for binding of LARP4B to this stretch, a deletion mutant, CKB del, was used. A nontarget RNA sequence, TOP3B, was used to control for specificity. (D) LARP4B binds to target mRNA sequence. CKB RNA sequence was incubated with increasing amounts of recombinant LARP4B. The unbound and bound RNA was separated by native gel electrophoresis and detected by autoradiography, confirming binding of LARP4B to target RNA sequence. (E) Quantification of LARP4B binding to CKB RNA resulted in a dissociation constant $\left(K_{\mathrm{d}}\right)$ of $\sim 200 \mathrm{nM}$. $(F)$ Using the CKB deletion mutant missing the U-rich stretch did not result in LARP4B binding, showing the dependency of AU-rich sequences for the interaction. $(G)$ Electromobility shift assay with TOP3B RNA did not result in LARP4B binding confirming the specificity of LARP4B binding to target sequences.

changes, confirming the stabilization effect of LARP4B on its target transcripts (Fig. 4C). In conclusion, these data suggest that LARP4B-binding to its target mRNAs leads to their stabilization.

\section{Stabilization of LARP4B targets enables their translation}

To analyze if the stabilization of target mRNAs by LARP4B results in changes in the corresponding protein levels, a pSILAC (pulsed stable isotope labeling by amino acids in cell culture) experiment was performed. HEK293 cells initially grown in medium containing the "light" version of arginine and lysine (Arg0, Lys0) were transfected with either LARP4B siRNA or control siRNA. Forty-eight hours after siRNA transfection, the cell culture media were exchanged to medium containing "medium" (Arg6, Lys4) or "heavy" (Arg10, Lys8) labeled amino acids and cells were harvested af- ter further $24 \mathrm{~h}$. During this period synthesized proteins are metabolically labeled with either the "medium" or "heavy" versions of arginine and lysine. Prepared cell extracts were combined and tryptic peptides analyzed by mass spectrometry (nanoLC-MS/MS). The abundance ratios between the "medium" (LARP4B siRNA) and "heavy" (control siRNA) labeled proteins reflect the differences in protein synthesis rates between the two samples. Next, the changes in protein synthesis rate of the top 500 LARP4B targets were compared with the remaining genes in a cumulative distribution function. The knockdown of LARP4B resulted in a statistically significant decrease in target mRNA protein synthesis compared with controls (Fig. $4 \mathrm{D})$. Considering the stabilization of the target mRNAs by LARP4B this effect is probably due to an increase in mRNA levels rather than directly on translation.

\section{LARP4B, LARP4, and LARP1 interact with an overlapping set of mRNAs}

The LARP family members LA, LARP1, LARP4, LARP4B, and LARP6 are all linked to mRNA metabolism. Of note, of this group, LARP1 and LARP4 display very similar characteristics if compared with LARP4B as they are mostly cytoplasmic, interact with PABPC1 and associate with actively translating ribosomes (Angenstein et al. 2002; Burrows et al. 2010; Schäffler et al. 2010; Yang et al. 2011). This raised the possibility that these proteins target a common set of mRNAs and perform synergistic or redundant functions. To test this possibility the interaction of LARP1, LARP4, and LARP4B with selected mRNAs was compared. To this end, Flag/HA-tagged LARP1, LARP4, and LARP4B were immunoprecipitated from cell extract of stable cell lines using anti-Flag antibodies and copurified mRNAs were analyzed by RT-PCR. Of note, LARP4 and LARP4B have a specific set of interacting mRNAs in common (Fig. 5A, compare lanes 2 and 6). Furthermore, also the set of nontarget mRNAs appear to overlap, the only exception being the XPO6 mRNA, which is weakly bound by LARP4 only (Fig. 5A, lanes 2 and 6). LARP1 also contacts the mRNA pool bound by LARP4 and $4 \mathrm{~B}$ (Fig. 5A, compare lanes 2, 6, and 10). In addition, LARP1 associates with mRNA transcripts not bound by LARP4 and 4B, namely DDX6, XPO1, TOP2A, and RCOR1. Thus, all three LARPs interact with an overlapping set of mRNAs but each LARP may also have a set of specific targets. 
A

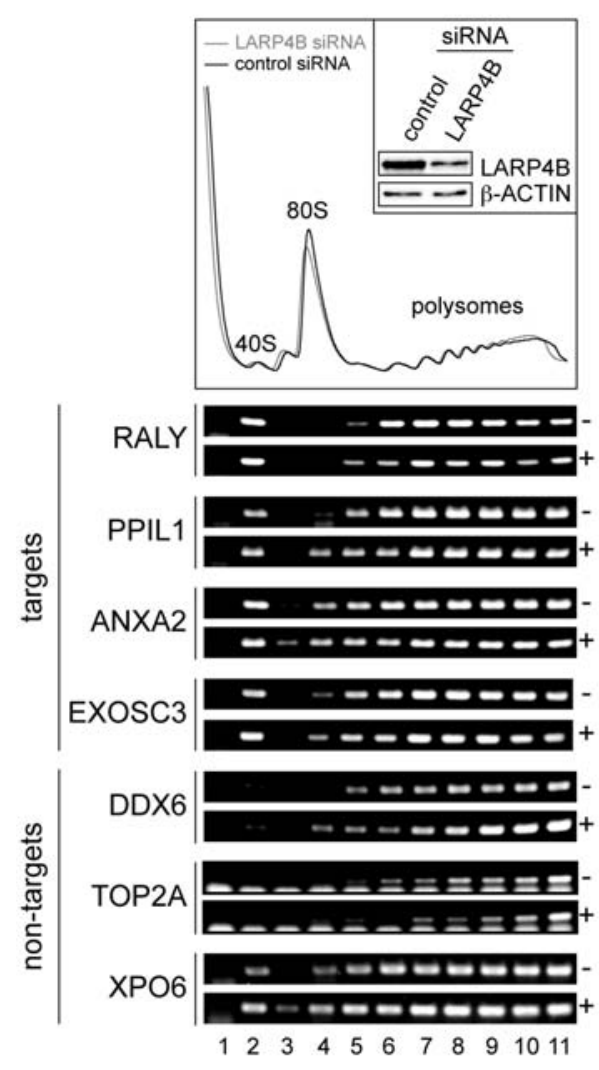

B
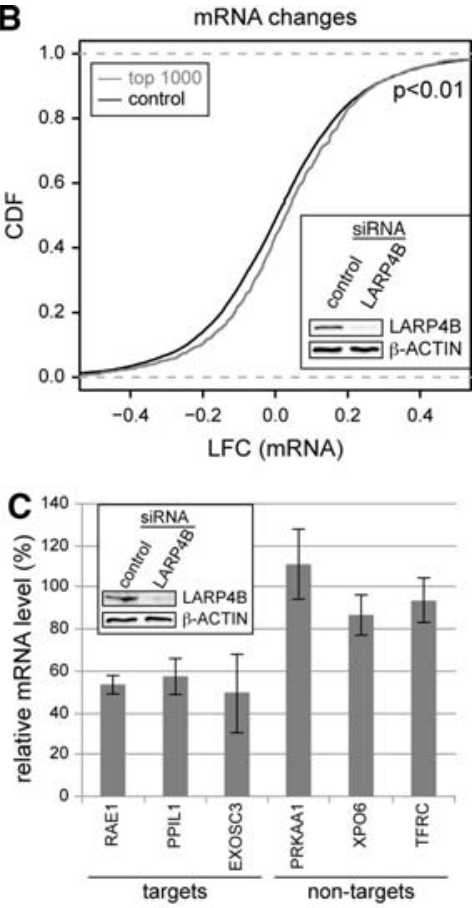

D changes in protein synthesis (pSILAC)

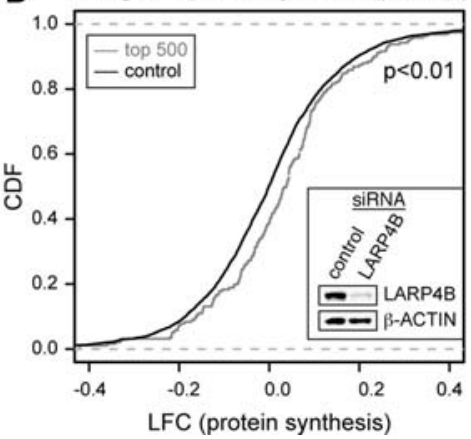

FIGURE 4. LARP4B increases target mRNA expression. (A) LARP4B does not affect association of mRNAs with the translation machinery. Cell extract of LARP4B knockdown $(+)$ and control cells (-) were separated by density gradient centrifugation. Absorption profiles at $260 \mathrm{~nm}$ are shown indicating migration of $40 \mathrm{~S}, 80 \mathrm{~S}$, and polysomes. RNA of the gradient fractions was extracted and analyzed by RT-PCR. The LARP4B knockdown does not affect sedimentation behavior of the analyzed mRNAs. (Inset) Knockdown of LARP4B was analyzed by Western blotting using anti-LARP4B and anti-actin antibodies. (B) LARP4B stabilizes target mRNAs. mRNA of LARP4B knockdown and control cells was isolated and analyzed by RNA-seq. Log2 fold changes in mRNA levels of top 1000 target mRNAs were compared with the remainder mRNAs in a cumulative distribution function (CDF) which shows a significant destabilization of the target mRNAs upon LARP4B knockdown. (Inset) Western blot to control for efficient LARP4B knockdown using anti-LARP4B and anti-actin antibodies. $(C)$ Effect of LARP4B on target mRNA levels. RNA of LARP4B knockdown and control cells was isolated and relative mRNA levels of target and nontarget mRNAs were determined by qPCR confirming the stabilizing effect of LARP4B on analyzed target mRNAs. (Inset) Cell extracts of LARP4B knockdown and control cells were analyzed by Western blotting using anti-LARP4B and anti-actin antibodies. $(D)$ Impact of LARP4B on the proteome. To analyze the effect of LARP4B in a proteome-wide scale a PSILAC assay was performed. Newly synthesized proteins in LARP4B knockdown cells were labeled using mediumheavy amino acids and in control cells using heavy amino acids. Differences in protein expression rates between LARP4B knockdown and control samples were assessed by mass spectrometry. Log2 fold changes in protein expression rate of the top 500 LARP4B targets were compared with the rest in a CDF. LARP4B knockdown leads to a significant decrease in target gene expression. (Inset) Western blot to analyze for LARP4B knockdown efficiency using anti-LARP4B and anti-actin antibodies.

The overlapping set of target mRNAs pointed toward related or even redundant cellular functions of these LARPs. To test this possibility, the influence of a LARP1, LARP4, and LARP4B knockdown and combinations thereof on the expression of a luciferase reporter was analyzed. This reporter contains the $3^{\prime}$ UTR of SAT1, which is a target mRNA of all three LARPs. The relative luciferase activity was determined and found to be reduced by $70 \%, 20 \%$, and $42 \%$ upon knockdown of LARP1, LARP4, and LARP4B, respectively (Fig. 5B). These results confirm the previously reported stimulatory effect of these LARPs on gene expression (Burrows et al. 2010; Schäffler et al. 2010; Yang et al. 2011; Aoki et al. 2013; Mura et al. 2014; Tcherkezian et al. 2014). The simultaneous knockdown of LARP4 and LARP4B led to a decrease in the luciferase activity by $55 \%$. Combining the LARP 1 knockdown with LARP4 or LARP4B resulted in $79 \%$ and $72 \%$ suppression of luciferase activity, respectively. The knockdown of all three LARPs at once showed the most drastic effect with over $82 \%$ decrease in luciferase activity. The inhibitory effect of the luciferase reporter is hence slightly more pronounced for the combination of the knockdown of the LARP4/4B and LARP1/4 pairs whereas only marginal effects were observed in case of a LARP4B and LARP1 knockdown. However, we observed an increased expression of LARP4 and LARP1 when the two other LARP proteins or combinations thereof were knocked down. This might minimize the observed negative effects under knockdown conditions.

\section{DISCUSSION}

In this study, we have taken a systematic approach to identify the in vivo RNA targets of LARP4B. As LARP4B contains the La module it was considered a bona fide (m)RNA-binding protein but previous studies had detected only interactions with PABPC1 and RACK1 (Angenstein et al. 2002; Schäffler et al. 2010). By applying PAR-CLIP we observed efficient crosslinking of LARP4B to RNA in vivo in addition to these previously reported protein-protein interactions. RNA-seq 

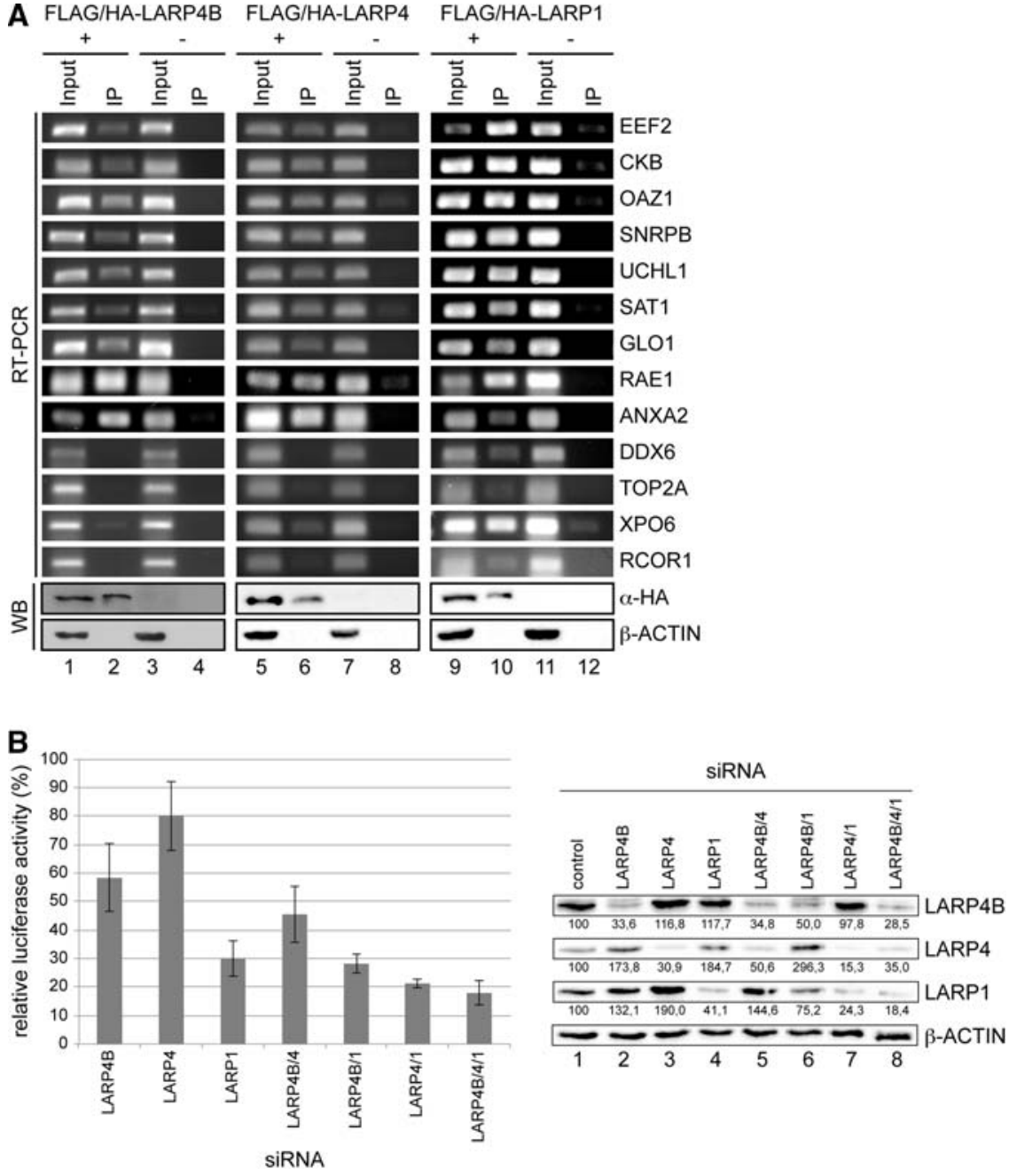

FIGURE 5. The La-related proteins LARP4B, LARP4, and LARP1 interact with an overlapping set of mRNAs. (A) Comparison of interacting mRNAs of the LARP4B, LARP4, and LARP1 proteins. To identify mRNAs bound by LARP4 and LARP1, the FLAG/HA-tagged proteins were immunoprecipitated from cell extract of stably overexpressing HEK293 cell lines (lanes 6 and 10). For control a nonoverexpressing HEK293 cell line was used (lanes 8 and 12). The copurified RNA was analyzed by RT-PCR, which revealed an overlapping set of target mRNAs for the La-related proteins 4B, 4, and 1 (LARP4B immunoprecipitation identical to Fig. 2A). Western blot analysis confirmed the immunoprecipitation of the antigens. (B) Effect of LARP4B, LARP4, and LARP1 on luciferase reporter expression. LARP4B, LARP4, and LARP1 and combinations thereof were knocked down and a reporter plasmid encoding a firefly luciferase was transiently transfected. Relative luciferase activity of the prepared extracts was determined (left panel). Results were deduced from at least three independent biological replicates. A Western blot analysis confirmed the knockdown of LARP4B, LARP4, and LARP1 (right panel). Numbers indicate knockdown efficiency.

of crosslinked RNA fragments confirmed the notion that LARP4B is an mRNA-binding protein. As PAR-CLIP not only allows the detection of stable but also of weak and transient interactions, the obtained set of mRNA-targets was very large. mRNAs stably bound to LARP4B were defined by combining the PAR-CLIP data set with an independent data set obtained by RIP-PCR, allowing the definition of a high-confidence mRNA interactome (see Fig. 2).

The distribution of the LARP4B-binding sites along the mRNAs revealed a preferential binding of LARP4B to AU- rich sequences within $3^{\prime}$ UTRs. However, a sequence bias because of the use of $4 \mathrm{SU}$ has to be kept in mind. Binding to $3^{\prime}$ UTRs was interesting in the light of our earlier finding of an interaction between LARP4B with the poly(A)-tail binding protein PABPC1 (Schäffler et al. 2010). This raises the possibility that LARP4B becomes co-recruited to the $3^{\prime}$ UTR of mRNP via direct interactions of LARP4B with the RNA target sequence as well as adjacently bound to PABPC1.

While we were able to define the RNA element required for LARP4B binding, it is still unknown which part of the protein mediates this interaction. For the genuine La protein (LARP3) it was shown that the La module consisting of the La motif and the adjacent RRM is required and sufficient to bind $3^{\prime}$-UUUOH (Bayfield et al. 2010). Alignment of the La modules of human LARP3 and LARP4B proteins showed that some of the amino acids needed for $3^{\prime}$-UUUOH binding are not conserved in the LARP4B protein (Bousquet-Antonelli and Deragon 2009; Bayfield et al. 2010). Furthermore, LARP4B contains an RRM-like domain instead of a classical RRM (BousquetAntonelli and Deragon 2009). Nevertheless, in the absence of any other defined RNA-binding domain we consider it likely that the La module of LARP4B enables RNA binding. A high-resolution structure of LARP4B bound to its RNA target is needed to understand in detail how these molecules interact and such studies are currently underway.

Previous studies indicated that LARP4B acts as a positive factor of translation but its mode of action remained unclear (Schäffler et al. 2010). The systematic identification of mRNA targets presented in this study enabled first insight into how LARP4B exerts this effect. A direct effect on translation appeared unlikely, since the reduction of LARP4B by RNA interference did not affect the association of target mRNAs with the translation machinery (Fig. 4A). As this study was not performed in a transcriptome-wide scale but only for selected mRNAs a translational effect cannot be ruled out completely. However, a transcriptome-wide analysis revealed a significant reduction of the levels of LARP4B-bound mRNAs under LARP4B knockdown conditions (Fig. 4B). This finding could be confirmed by real-time PCR analyses of selected mRNAs (Fig. 4C). As 
LARP4B is mostly cytosolic and hence unlikely to affect transcription, the changes in mRNA levels are most likely due to alterations in their stability. Of note, the reduced stability of mRNA targets leads to a reduced translation of the encoded transcripts into proteins (Fig. 4D). These findings are in good agreement with our previous characterization of LARP4B as a positive factor of the post-transcriptional gene expression.

Data gained in this study revealed a stimulatory effect of LARP4B on the expression of target mRNAs based on the stabilization of the bound transcripts. This effect can be explained by the interaction of LARP4B with the $3^{\prime}$ UTRs of target mRNAs, which in turn may result in an increased interaction of LARP4B with PABPC1. Upon binding to the poly(A) tail PABPC1 serves as a scaffold for various proteins influencing both translation and stability of the mRNA, among them eIF4G, PAN3, PAIP1, PAIP2, and TNRC6A. Those factors are capable of either stimulating or repressing mRNA expression. By competing for PABPC1 binding they influence the expression efficiency of the mRNA. A similar mechanism might explain the stabilizing effect of LARP4B. Notably the displacement of destabilizing factors such as TNRC6A or deadenylation factors such as the PAN2/PAN3 complex by the LARP4B protein might contribute to the stabilization of the mRNA.

The interaction of LARP4B with AU-rich sequences in the 3' UTRs of the target mRNAs might also point to a role of LARP4B in the metabolism of AU-rich elements (ARE) containing mRNAs. AREs are 50-100-nt spanning regions in the $3^{\prime}$ UTR of mRNAs coding for example for transcription factors or cytokines. Being bound by various factors such as tristetraprolin (TTP), AUF1 or HuR/ELAVL1, AREs affect the stability of the mRNA decisively. The majority of the interacting factors, e.g., TTP and AUF1 cause the destabilization of the mRNA by recruiting components of the degradation machinery and thus favor the decay of ARE-containing mRNA. mRNA stability can also be augmented by ARE interacting factors. The best-characterized example is the HuR protein, which competes with destabilizing factor for the binding to AREs and leads to the stabilization of the mRNA presumably by displacement of these factors (Lebedeva et al. 2011; Mukherjee et al. 2014). Likewise, binding of LARP4B to AU-rich sequences in the context of AREs might displace destabilizing factors similarly to the mechanism described for HuR.

It is estimated that AREs are found in several thousand mRNAs matching the large number of identified LARP4B target mRNAs. Moreover, it is conceivable that LARP4B contacts AU-rich sequences not included in AREs and thus influences the expression of a wider scale of mRNAs. In a similar way, HuR was recently shown to bind to over 4800 target mRNAs and hence a role for HuR beyond the metabolism of ARE-containing mRNAs was proposed (Lebedeva et al. 2011).

In addition to the $3^{\prime}$ UTR there are also binding sites found in the $5^{\prime}$ UTR and coding sequence. The function of LARP4B binding to these regions is still unclear and needs further investigation.

Similar biochemical and functional properties were reported for LARP4B, LARP4, and LARP1. They are cytoplasmic proteins that translocate into stress granules under cellular stress conditions, interact with PABPC1, associate with actively translating ribosomes and exert stabilizing effects on target mRNAs (Burrows et al. 2010; Schäffler et al. 2010; Yang et al. 2011; Aoki et al. 2013; Mura et al. 2014; Tcherkezian et al. 2014). This suggests that they might fulfill overlapping or redundant functions in mRNA metabolism. In agreement with this notion, we showed that LARP4B, LARP4, and LARP1 bind a common set of target mRNAs although they might also have specific mRNA sets they interact with. However, the simultaneous inactivation of LARP pairs showed only minor additive, rather than synergistic effects. Thus, despite of targeting a common set of mRNAs, the LARPs $4 \mathrm{~B}, 4$ and 1 are likely to perform similar but nonredundant functions.

\section{MATERIALS AND METHODS}

\section{Cloning, recombinant protein expression, and antibodies}

For generation of stable cell lines LARP1 and LARP4, cDNAs were cloned into a pcDNA5/FRT/TO plasmid (Invitrogen) containing an N-terminal Flag/HA-tag. For the generation of the pHA-FF luciferase reporter, the firefly luciferase gene (luc+) was cloned into a pHA vector (a derivative of pcDNA3.1 [Invitrogen], allowing generation of N-terminally tagged HA proteins) followed by the SAT1 $3^{\prime}$ UTR.

For expression of recombinant LARP4B, pGEX-6P-1-LARP4B (Schäffler et al. 2010) was transfected into E. coli BL21(DE3)pLysS and grown to an $\mathrm{OD}_{600}$ of 0.4 . After induction with $1 \mathrm{mM}$ IPTG for $5 \mathrm{~h}$ at $15^{\circ} \mathrm{C}$, bacteria were pelleted and resuspended in lysis buffer (50 mM Tris $\mathrm{HCl}$ at $\mathrm{pH} 7.5,100 \mathrm{mM} \mathrm{NaCl}, 1 \%$ [v/v] Triton-X 100, $1 \mathrm{mM}$ DTT, and complete EDTA-free protease inhibitor cocktail [Sigma-Aldrich]). After sonication, the cleared lysate was incubated with Glutathione Sepharose (GE Healthcare), washed with lysis buffer and equilibrated with $100 \mathrm{mM} \mathrm{NaCl}, 50 \mathrm{mM}$ Tris $\mathrm{HCl}$ at $\mathrm{pH}$ 6.7, and $1 \mathrm{mM}$ DTT. LARP4B was cleaved off the beads by PreScission protease treatment. For further purification, anion exchange chromatography was applied using a HighTrapQ HP column (GE Healthcare) followed by size exclusion chromatography on a Superdex 200 10/300 GL column (GE Healthcare) in 150 $\mathrm{mM} \mathrm{NaCl}, 50 \mathrm{mM}$ Tris HCL at $\mathrm{pH}$ 7.5, and $1 \mathrm{mM}$ DTT.

For Western blotting and immunoprecipitation a polyclonal LARP4B antibody was used (Schäffler et al. 2010). Commercial primary antibodies were purchased from Abcam (LARP1), Bethyl Laboratories (LARP4), HiSS Diagnostics (HA), and Sigma-Aldrich ( $\beta$-Actin).

\section{Generation of stable cell lines and cell culture}

Stable HEK293 cell lines were generated using the Flp-In T-REx core kit as described (Schäffler et al. 2010). Stable cell lines were grown in 
DMEM containing 10\% FCS, $10 \mu \mathrm{g} / \mathrm{mL}$ blasticidine, and $100 \mu \mathrm{g} / \mathrm{mL}$ hygromycin B. Flp-In T-REx 293 cells were cultivated in DMEM containing $10 \%$ FCS, $10 \mu \mathrm{g} / \mathrm{mL}$ blasticidine, and $100 \mu \mathrm{g} / \mathrm{mL}$ Zeocin and HEK293 cells in DMEM containing 10\% FCS and 1\% Pen/Strep.

For transfection of plasmid DNA the Nanofectin kit (GE Healthcare) was used. siRNAs targeting LARP4B and LARP4 were purchased from Thermo Fisher Scientific. siRNAs against LARP1 [GAAUGGAGAUGAGGAUUGC(dTdT)], firefly luciferase [CGU ACGCGGAAUACUUCGA(dTdT)], and GFP [GCAAGCUGA CCCUGAAGUUC(dTdT)] were synthesized by Eurofins MWG Operon. siRNA was transfected using the Lipofectamine RNAi Max kit (Life Technologies).

For preparation of cell extracts, cells were washed with PBS and harvested using lysis buffer. After incubation for $10 \mathrm{~min}$ on ice the extracts were centrifuged $\left(10 \mathrm{~min}, 9000 \mathrm{~g}, 4^{\circ} \mathrm{C}\right)$ to remove cell debris and the supernatant was used in downstream applications.

\section{Electromobility shift assay}

Oligoribonucleotides were radioactively labeled at the $5^{\prime}$ end using $\mathrm{T} 4$ polynucleotide kinase and $\left[\gamma^{-}{ }^{32} \mathrm{P}\right]-\mathrm{ATP}$ and purified by denaturing gel electrophoresis. Labeled RNA ( $5 \mathrm{nM})$ was incubated with purified recombinant LARP4B in $1 \times$ EMSA buffer $(50 \mathrm{mM}$ Tris $\mathrm{HCl}$ at $\mathrm{pH}$ 7.5, $100 \mathrm{mM} \mathrm{NaCl}, 1 \mathrm{mM}$ DTT, 10\% [v/v] glycerin, $0,1 \mathrm{mg} / \mathrm{mL}$ $\mathrm{BSA}$ ) for $30 \mathrm{~min}$ at $4^{\circ} \mathrm{C}$. RNA was separated on a $0.4 \%$ native agarose gel and visualized by autoradiography.

\section{CKB 5'-GUAGAGACUUCCGUCACGCUUGGUAGAGUUUA UUUUUUUGA-3'}

CKB del 5'-GUAGAGACUUCCGUCACGCUUGGUAGAGGA- $3^{\prime}$ TOP3B 5'-GACCCUGUCCUCCCUCACCCAGGCUGCAGUGC CAUGCAGAC- $3^{\prime}$

\section{Real-time PCR}

siRNAs against LARP4B and firefly luciferase were transfected in HEK293 cells. Forty-eight hours post-transfection cell extracts were prepared, RNA was isolated by phenol extraction, and DNA was hydrolyzed using the TURBO DNA-free kit (Life Technologies). For generation of cDNA Superscript III reverse transcriptase (Invitrogen) and random hexamer primers were used. Real-time PCR was performed with the CFX96 Touch Real-Time PCR Detection System (Bio-Rad) and universal SYBR Green Supermix (Bio-Rad). All reactions were run in triplicate. Ct values were calculated using the CFX Manager 2.0 software. Values were normalized to SDHA expression. The evaluation was performed using the $\Delta \Delta \mathrm{ct}$ method.

\section{RNA-seq}

HEK293 cells were transfected with siRNA targeting LARP4B and firefly luciferase. Forty-eight hours after transfection total RNA was prepared using the RNeasy mini kit (Qiagen) and mRNA was isolated with the NEBNext poly(A) mRNA Magnetic Isolation Module (New England BioLabs). cDNA libraries were prepared using NEBNext mRNA Library Prep Master Mix Set for Illumina (New England BioLabs). cDNA was amplified with NEBNext Multiplex Oligos for Illlumina (15 cycles) and sequencing was performed on a Genome Analyzer IIX (Illumina) using TruSeq SR Cluster kit v5-CS-GA (Illumina) and TruSeq SBS kit v5-GA (Illumina). For bioinformatic analyses fastq files were extracted using Casava and reads were assigned to particular conditions based on their index sequences (deconvoluted). Reads were aligned against the human genome (hg19) using bowtie-0.12.8 and bowtie default options. Further analysis was performed with samtools and $\mathrm{R}$ using Rsamtools, Genomicfeatures, edgaR, limma, biomaRt, and lattice.

\section{PAR-CLIP}

For PAR-CLIP experiments a tetracycline-inducible HEK293 cell line was used for inducible expression of N-terminally Flag/HAtagged LARP4B (Schäffler et al. 2010). Cells were cultivated overnight in medium containing $100 \mu \mathrm{M} 4 \mathrm{SU}$ and expression of Flag/ HA-LARP4B was induced with $0.5 \mu \mathrm{g} / \mathrm{mL}$ tetracycline for 5 h. PAR-CLIP was performed as described (Hafner et al. 2010). UV-irradiated cells were lysed in NP-40 lysis buffer $(50 \mathrm{mM}$ HEPES- $\mathrm{KOH}$ at $\mathrm{pH} 7.4,150 \mathrm{mM} \mathrm{KCl}, 2 \mathrm{mM}$ EDTA, $0.5 \%[\mathrm{v} / \mathrm{v}$ ] NP40, 0.5 mM DTT, complete EDTA-free protease inhibitor cocktail [Roche]). After treatment with RNaseT1 (Fermentas) at a final concentration of 2 units/ $\mu \mathrm{L}$ for $7 \mathrm{~min}$, immunoprecipitation was carried out with Anti-Flag Magnetic beads (SIGMA) for $1 \mathrm{~h}$ at $4^{\circ} \mathrm{C}$. Following an additional RNaseT1 treatment (final concentration 2 units $/ \mu \mathrm{L}$ ) for $7 \mathrm{~min}$ the beads were incubated with calf intestinal phosphatase (NEB) and RNA fragments were radioactively end-labeled using T4 polynucleotide kinase (Fermentas) and $\left[\gamma^{-}{ }^{32} \mathrm{P}\right]$-ATP. The crosslinked protein-RNA complexes were resolved on a $4 \%-12 \%$ NuPAGE gel (Invitrogen). The SDS-PAGE gel was transferred to a nitrocellulose membrane (Whatman) and the protein-RNA complex migrating at an expected molecular weight was excised. RNA was isolated by Proteinase K (Roche) treatment and phenol-chloroform extraction. In subsequent steps, a $3^{\prime}$ adapter and $5^{\prime}$ adapter were ligated to the isolated RNA. Adapter-ligated RNA was reverse transcribed and PCR-amplified. The amplified cDNA was sequenced on a HighSeq2000 (Illumina) with a $1 \times$ $51 \mathrm{nt}$ cycle.

The PAR-CLIP cDNA sequencing data were analyzed using the PAR-CLIP analysis pipeline (Lebedeva et al. 2011). Filtering was performed to obtain $\mathrm{RC} 3 \mathrm{H} 1$ clusters sites at an estimated $5 \%$ false-positive rate. Read alignment statistics, cluster length distribution, target gene identification, cluster distribution, cluster coverage profiles were generated by the PAR-CLIP analysis pipeline (Lebedeva et al. 2011). For each cluster the position with the highest number of diagnostic transition events was determined and defined as the preferred crosslink site. For motif analysis, 7 mer occurrences were counted in $20 \mathrm{nt}$ upstream of and downstream from the preferred crosslink site of the top $10003^{\prime}$ UTR-binding cluster using a custom Perl script. mRNA targets identified by PAR-CLIP were ranked based on the number of $\mathrm{T}$ to $\mathrm{C}$ transitions and normalized by mRNA expression levels (Gregersen et al. 2014). These data were intersected with pulsed SILAC or mRNA-seq experiment using top 500 and top 1000 target mRNAs, respectively.

\section{mRNA fractionation assay}

Forty-eight hours after transfection of siRNAs targeting LARP4B and firefly luciferase HEK293 cells were treated with $8 \mu \mathrm{g} / \mathrm{mL}$ emetine for 5 min. Hereafter, cells were washed with cold PBS and cell 
extracts were prepared using gradient lysis buffer $(100 \mathrm{mM} \mathrm{KCl}, 20$ $\mathrm{mM}$ Tris $\mathrm{HCl}$ at $\mathrm{pH} 7.5,5 \mathrm{mM} \mathrm{MgCl}_{2}, 0.01$ units/ $\mu \mathrm{L}$ RNasin, $0.5 \%$ [v/v] NP-40, $0.1 \mathrm{mg} / \mathrm{mL}$ cycloheximide, $1 \mathrm{mM}$ DTT, complete EDTA-free protease inhibitor cocktail [Sigma-Aldrich]). Cell extracts were separated by centrifugation on a $5 \%-45 \%$ sucrose gradient (SW40Ti, $38000 \mathrm{rpm}, 1 \mathrm{~h}, 4^{\circ} \mathrm{C}$ ). RNA was isolated from gradient fractions and reverse transcribed using Superscript III (Life Technologies). cDNA was amplified by PCR and analyzed by agarose gel electrophoresis.

\section{RIP-PCR}

Stable Flp-In T-REx-293 LARP4B, LARP4, and LARP1 cells were induced with $0.5 \mu \mathrm{g} / \mathrm{mL}$ tetracycline for $5 \mathrm{~h}$. Flp-In T-REx-293 cells were used for control reactions. Cells were harvested and lysed in lysis buffer $(150 \mathrm{mM} \mathrm{NaCl}, 50 \mathrm{mM}$ Tris $\mathrm{HCl}$ at $\mathrm{pH} 7.5,2.5 \mathrm{mM}$ $\mathrm{MgCl}_{2}, 0.5 \%$ [v/v] NP-40, $1 \mathrm{mM}$ DTT, complete EDTA-free protease inhibitor cocktail [Sigma-Aldrich]). Lysates were prepared and immunoprecipitations of Flag/HA-tagged proteins were performed using ANTI-Flag magnetic beads (Sigma-Aldrich). Endogenous LARP4B was immunoprecipitated from HEK293 cell extract with anti-LARP4B antibodies coupled to protein-G Sepharose. As a control pre-immune serum was used. Beads were incubated in cell extract for $90 \mathrm{~min}$ at $4^{\circ} \mathrm{C}$. After washing with lysis buffer coprecipitated RNA was isolated from beads and input control using phenol extraction. cDNA was generated using Superscript III reverse transcriptase (Life Technologies) and amplified by PCR. To control for IP efficiency immunoprecipitated proteins were separated by SDS-PAGE and analyzed by Western blot analysis.

\section{PSILAC}

HEK293 cells were transfected with siRNAs against LARP4B and firefly luciferase. Twenty-four hour post-transfection cells were washed twice with PBS and cultivated in light medium (DMEM, 10\% FCS, 4 mM glutamine, $1.74 \mathrm{mM}$ L-proline, $0.8 \mathrm{mM}$ L-lysine, $0.4 \mathrm{mM}$ L-arginine). Forty-eight hours post-transfection cells were washed twice with PBS and LARP4B knockdown cells were cultivated in medium-heavy medium (DMEM, 10\% FCS, 4 mM glutamine, $1.74 \mathrm{mM}$ L-proline, $0.8 \mathrm{mM}$ L-lysine [4,4,5,5-D4], $0.4 \mathrm{mM} \mathrm{L}$-arginine [U-13C6]) while control cells were cultivated in heavy medium (DMEM, 10\% FCS, $4 \mathrm{mM}$ glutamine, $1.74 \mathrm{mM}$ L-proline, $0.8 \mathrm{mM}$ L-lysine [U-13C6, 15N2], 0.4 mM L-arginine [U-13C6, 15N4]) for $24 \mathrm{~h}$. Cells were washed with PBS and cell extracts were prepared using lysis buffer $(150 \mathrm{mM} \mathrm{NaCl}, 50 \mathrm{mM}$ Tris $\mathrm{HCl}$ at $\mathrm{pH} 7.5,2.5 \mathrm{mM}$ $\mathrm{MgCl}_{2}, 0.5 \%$ [v/v] NP-40, $1 \mathrm{mM}$ DTT, complete EDTA-free protease inhibitor cocktail [Sigma-Aldrich]). For in gel digests proteins were reduced and alkylated prior to SDS-PAGE by heating the cell lysates for $10 \mathrm{~min}$ at $70^{\circ} \mathrm{C}$ in NuPAGE LDS sample buffer (Life Technologies) supplemented with $50 \mathrm{mM}$ DTT. Samples were alkylated by adding $120 \mathrm{mM}$ iodoacetamide solution and incubated for $20 \mathrm{~min}$ at room temperature. Samples were loaded on NuPAGE Novex Bis-Tris 4\%-12\% gradient gels (Life Technologies) and stained with Coomassie (Simply Blue, Life Technologies). Whole lanes were cut into 15 bands. The bands were destained with $30 \%$ acetonitrile, shrunk with $100 \%$ acetonitrile, and dried in a vacuum concentrator. Digests with $0.1 \mu \mathrm{g}$ trypsin (Promega) per gel band were performed overnight at $37^{\circ} \mathrm{C}$ in $50 \mathrm{mM}$ ammonium bicarbonate $(\mathrm{ABC})$ buffer. Peptides were extracted from the gel slices with 5\% formic acid. NanoLC-MS/MS analyses were performed on an LTQ-
Orbitrap Velos Pro mass spectrometer equipped with an EASYSpray ion source and coupled to an EASY-nLC 1000 UHPLC system (all Thermo Scientific). Peptides were loaded on a trapping column $(2 \mathrm{~cm} \times 75 \mu \mathrm{m}$ ID, PepMap C18 $3 \mu \mathrm{m}$ particles, $100 \AA$ pore size $)$ and separated on an EASY-Spray column $(25 \mathrm{~cm} \times 75 \mu \mathrm{m}$ ID, PepMap C18 $2 \mu \mathrm{m}$ particles, $100 \AA$ pore size) with a 120 min linear gradient from $3 \%$ to $30 \%$ acetonitrile, $0.1 \%$ formic acid, and $400 \mathrm{~nL} / \mathrm{min}$ flow rate. MS scans were acquired in the Orbitrap analyzer with a resolution of 30.000 at $\mathrm{m} / \mathrm{z}$ 400, MS/MS scans were acquired in the LTQ Velos analyzer using CID fragmentation. A TOP15 data-dependent MS/MS method was used; dynamic exclusion was applied with a repeat count of 1 and an exclusion duration of 60s. Singly charged precursors were excluded from the selection. Minimum signal threshold for precursor selection was set to 10.000. Predictive AGC was used with an AGC target value of $1 \times 10^{6}$ for MS scans and $1 \times 10^{4}$ for MS/MS scans. Lock mass option was applied for internal calibration using background ions from protonated decamethylcyclopentasiloxane (m/z 371.10124). For protein identification and quantitation, raw MS data files were analyzed with MaxQuant version 1.5.0.25 (Cox and Mann 2008). Database search was performed with the integrated search engine Andromeda. UniProt human reference proteome database was used in combination with a database containing common contaminants as a reverse concatenated targetdecoy database. Protein identification was under control of the falsediscovery rate $(<1 \%$ FDR on protein and peptide level). In addition to MaxQuant default settings (e.g., at least 1 razor/unique peptide for identification, two allowed miscleavages), the search was performed against following variable modifications: protein N-terminal acetylation, Gln to pyro-Glu formation, and oxidation (on Met). For quantitation of pSILAC-labeled proteins, the median of the log2transformed normalized peptide ratios heavy to median (H/M) for each protein was calculated. At least two ratio counts were required for protein quantitation. Protein ratios were normalized for each experiment in intensity bins (at least 300 proteins per bin).

\section{In vivo luciferase reporter gene assay}

HEK293 cells were transfected with siRNAs targeting LARP4B, LARP4 or LARP1 and combinations thereof. For control a siRNA against GFP was used. Forty-eight hours post-transfection a pHAFF reporter plasmid was transfected. Five hours later cell extracts were prepared as described above and luciferase activity was determined by using a standard chemoluminescence detection procedure at a TriStar LB941 luminometer (Berthold Technologies).

\section{DNA oligonucleotides used for cDNA amplification}

$\begin{array}{ll}\text { EEF2 for } & \text { CATCTACGGGGTTTTGAACAGG } \\ \text { EEF2 rev } & \text { TTCTTTCAGGCCCTTGCGCTTG } \\ \text { CKB for } & \text { AGTTCATGTGGAACCCTCACC } \\ \text { CKB rev } & \text { ACCAGCTCCACCTCTGAGAAG } \\ \text { OAZ1 for } & \text { ACTGGCGAACAGTGCTGAGTG } \\ \text { OAZ1 rev } & \text { CCGGTCTCACAATCTCAAAGC } \\ \text { SNRBP for } & \text { GAGGGACTCCAATGGGCATG } \\ \text { SNRBP rev } & \text { CAGACAATCCCATGAGACTCC } \\ \text { UCHL1 for } & \text { AATGTCGGGTAGATGACAAGGTG } \\ \text { UCHL1 rev } & \text { CACAGAGCATTAGGCTGCCTTG } \\ \text { SAT1 for } & \text { GGCAAGTTATTGTATCTTGAGGAC } \\ \text { SAT1 rev } & \text { GAAGTTGATGGATGGTTCATTCC }\end{array}$




$\begin{array}{ll}\text { GLO1 for } & \text { CTCGAGGATTCGGTCATATTGG } \\ \text { GLO1 rev } & \text { AGGAGAATTCTCACAGCACTAC } \\ \text { RAE1 for } & \text { GCTGCTGGGAAGTTCAAGAC } \\ \text { RAE1 rev } & \text { ATCACACGATGCCGTAAACA } \\ \text { RALY for } & \text { CTACCGGGACGACTTCTACG } \\ \text { RALY rev } & \text { GCAAAGAGCTTGACAGGTACG } \\ \text { PPIL1 for } & \text { GGTCGAGGTGGTGCATCTAT } \\ \text { PPIL1 rev } & \text { GAACTGGCTGCCATTGGTAT } \\ \text { ANXA2 for } & \text { ACAGCCATCAAGACCAAAGG } \\ \text { ANXA2 rev } & \text { TCAGTGCTGATGCAAGTTCC } \\ \text { EXOSC3 for } & \text { CAGACCAAATGTGCAGGTTG } \\ \text { EXOSC3 rev } & \text { CAGACCATCCTGTCCAATGA } \\ \text { DDX6 for } & \text { ATGATCGCTTCAACCTGAAAAG } \\ \text { DDX6 rev } & \text { ATGTGTCACAGATCCAAACGAG } \\ \text { TOP2A for } & \text { CCACTGTCTTCAAGCCCTCC } \\ \text { TOP2A rev } & \text { CGGTAGTGGAGGTGGAAGAC } \\ \text { XPO6 for } & \text { GACGCTCCATCACAACTGGA } \\ \text { XPO6 rev } & \text { TGTCCGAAAGCCTGCATGAT } \\ \text { RCOR1 for } & \text { CAGTAACCAGAAGCCTGTGAAG } \\ \text { RCOR1 rev } & \text { GATAACACAGTAGTCCACACC } \\ \text { PRKAA1 for } & \text { GGGTGAAGATCGGCCACTAC } \\ \text { PRKAA1 rev } & \text { CCTACCACATCAAGGCTCCG } \\ \text { TFRC for } & \text { TGGACAGCACAGACTTCACC } \\ \text { TFRC rev } & \text { ATCACGCCAGACTTTGCTGA } \\ \text { SDHA for } & \text { GATTACTCCAAGCCCATCCA } \\ \text { SDHA rev } & \text { CACAGTCAGCCTCGTTCAAA }\end{array}$

\section{SUPPLEMENTAL MATERIAL}

Supplemental material is available for this article.

\section{ACKNOWLEDGMENTS}

We thank Lee-Hsueh Hung and Albrecht Bindereif for advice in the biocomputational analysis of data. This work was supported by a grant from the Deutsche Forschungsgemeinschaft (DFG) to U.F. (Fi573-6/2).

Received February 18, 2015; accepted April 2, 2015.

\section{REFERENCES}

Aigner S, Cech TR. 2004. The Euplotes telomerase subunit p43 stimulates enzymatic activity and processivity in vitro. RNA 10: 11081118.

Aigner S, Postberg J, Lipps HJ, Cech TR. 2003. The Euplotes La motif protein $\mathrm{p} 43$ has properties of a telomerase-specific subunit. Biochemistry 42: 5736-5747.

Alfano C, Babon J, Kelly G, Curry S, Conte MR. 2003. Resonance assignment and secondary structure of an N-terminal fragment of the human La protein. J Biomol NMR 27: 93-94.

Alfano C, Sanfelice D, Babon J, Kelly G, Jacks A, Curry S, Conte MR. 2004. Structural analysis of cooperative RNA binding by the La motif and central RRM domain of human La protein. Nat Struct Mol Biol 11: 323-329.

Angenstein F, Evans AM, Settlage RE, Moran ST, Ling SC, Klintsova AY, Shabanowitz J, Hunt DF, Greenough WT. 2002. A receptor for activated $\mathrm{C}$ kinase is part of messenger ribonucleoprotein complexes associated with polyA-mRNAs in neurons. J Neurosci 22: 8827-8837.

Aoki K, Adachi S, Homoto M, Kusano H, Koike K, Natsume T. 2013. LARP1 specifically recognizes the $3^{\prime}$ terminus of poly(A) mRNA. FEBS Lett 587: 2173-2178.
Baltz AG, Munschauer M, Schwanhausser B, Vasile A, Murakawa Y, Schueler M, Youngs N, Penfold-Brown D, Drew K, Milek M, et al. 2012. The mRNA-bound proteome and its global occupancy profile on protein-coding transcripts. Mol Cell 46: 674-690.

Bayfield MA, Yang R, Maraia RJ. 2010. Conserved and divergent features of the structure and function of La and La-related proteins (LARPs). Biochim Biophys Acta 1799: 365-378.

Blagden SP, Gatt MK, Archambault V, Lada K, Ichihara K, Lilley KS, Inoue YH, Glover DM. 2009. Drosophila Larp associates with poly (A)-binding protein and is required for male fertility and syncytial embryo development. Dev Biol 334: 186-197.

Bousquet-Antonelli C, Deragon JM. 2009. A comprehensive analysis of the La-motif protein superfamily. RNA 15: 750-764.

Burrows C, Abd Latip N, Lam SJ, Carpenter L, Sawicka K, Tzolovsky G, Gabra H, Bushell M, Glover DM, Willis AE, et al. 2010. The RNA binding protein Larp1 regulates cell division, apoptosis and cell migration. Nucleic Acids Res 38: 5542-5553.

Cai L, Fritz D, Stefanovic L, Stefanovic B. 2010a. Binding of LARP6 to the conserved $5^{\prime}$ stem-loop regulates translation of mRNAs encoding type I collagen. J Mol Biol 395: 309-326.

Cai L, Fritz D, Stefanovic L, Stefanovic B. 2010b. Nonmuscle myosindependent synthesis of type I collagen. J Mol Biol 401: 564-578.

Castello A, Fischer B, Eichelbaum K, Horos R, Beckmann BM, Strein C, Davey NE, Humphreys DT, Preiss T, Steinmetz LM, et al. 2012. Insights into RNA biology from an atlas of mammalian mRNAbinding proteins. Cell 149: 1393-1406.

Chakshusmathi G, Kim SD, Rubinson DA, Wolin SL. 2003. A La protein requirement for efficient pre-tRNA folding. EMBO J 22: 6562-6572.

Challa AA, Stefanovic B. 2011. A novel role of vimentin filaments: binding and stabilization of collagen mRNAs. Mol Cell Biol 31: 3773-3789.

Copela LA, Fernandez CF, Sherrer RL, Wolin SL. 2008. Competition between the Rexl exonuclease and the La protein affects both Trf4pmediated RNA quality control and pre-tRNA maturation. RNA 14: $1214-1227$

Cox J, Mann M. 2008. MaxQuant enables high peptide identification rates, individualized p.p.b.-range mass accuracies and proteomewide protein quantification. Nat Biotechnol 26: 1367-1372.

Dong G, Chakshusmathi G, Wolin SL, Reinisch KM. 2004. Structure of the La motif: a winged helix domain mediates RNA binding via a conserved aromatic patch. EMBO J 23: 1000-1007.

Gregersen LH, Schueler M, Munschauer M, Mastrobuoni G, Chen W, Kempa S, Dieterich C, Landthaler M. 2014. MOV10 is a $5^{\prime}$ to $3^{\prime}$ RNA helicase contributing to UPF1 mRNA target degradation by translocation along 3' UTRs. Mol Cell 54: 573-585.

Hafner M, Landthaler M, Burger L, Khorshid M, Hausser J, Berninger P, Rothballer A, Ascano M Jr, Jungkamp AC, Munschauer M, et al. 2010. Transcriptome-wide identification of RNA-binding protein and microRNA target sites by PAR-CLIP. Cell 141: 129-141.

Intine RV, Sakulich AL, Koduru SB, Huang Y, Pierstorff E, Goodier JL, Phan L, Maraia RJ. 2000. Control of transfer RNA maturation by phosphorylation of the human La antigen on serine 366. Mol Cell 6: 339-348.

Keene JD. 2007. RNA regulons: coordination of post-transcriptional events. Nat Rev Genet 8: 533-543.

Kotik-Kogan O, Valentine ER, Sanfelice D, Conte MR, Curry S. 2008. Structural analysis reveals conformational plasticity in the recognition of RNA $3^{\prime}$ ends by the human La protein. Structure 16: 852-862.

Krueger BJ, Jeronimo C, Roy BB, Bouchard A, Barrandon C, Byers SA, Searcey CE, Cooper JJ, Bensaude O, Cohen EA, et al. 2008. LARP7 is a stable component of the 7SK snRNP while P-TEFb, HEXIM1 and hnRNP Al are reversibly associated. Nucleic Acids Res 36: 22192229.

Lebedeva S, Jens M, Theil K, Schwanhäusser B, Selbach M, Landthaler M, Rajewsky N. 2011. Transcriptome-wide analysis of regulatory interactions of the RNA-binding protein HuR. Mol Cell 43: $340-352$. 
Manojlovic Z, Stefanovic B. 2012. A novel role of RNA helicase A in regulation of translation of type I collagen mRNAs. RNA 18: 321334.

Markert A, Grimm M, Martinez J, Wiesner J, Meyerhans A, Meyuhas O, Sickmann A, Fischer U. 2008. The La-related protein LARP7 is a component of the 7SK ribonucleoprotein and affects transcription of cellular and viral polymerase II genes. EMBO Rep 9: 569-575.

Mukherjee N, Jacobs NC, Hafner M, Kennington EA, Nusbaum JD, Tuschl T, Blackshear PJ, Ohler U. 2014. Global target mRNA specification and regulation by the RNA-binding protein ZFP36. Genome Biol 15: R12.

Mura M, Hopkins TG, Michael T, Abd-Latip N, Weir J, Aboagye E, Mauri F, Jameson C, Sturge J, Gabra H, et al. 2014. LARP1 post-transcriptionally regulates mTOR and contributes to cancer progression. Oncogene doi: 10.1038/onc.2014.428.

Nykamp K, Lee MH, Kimble J. 2008. C. elegans La-related protein, LARP-1, localizes to germline P bodies and attenuates Ras-MAPK signaling during oogenesis. RNA 14: 1378-1389.

Prathapam R, Witkin KL, O’Connor CM, Collins K. 2005. A telomerase holoenzyme protein enhances telomerase RNA assembly with telomerase reverse transcriptase. Nat Struct Mol Biol 12: 252-257.

Schäffler K, Schulz K, Hirmer A, Wiesner J, Grimm M, Sickmann A, Fischer U. 2010. A stimulatory role for the La-related protein $4 \mathrm{~B}$ in translation. RNA 16: 1488-1499.

Sobel SG, Wolin SL. 1999. Two yeast La motif-containing proteins are RNA-binding proteins that associate with polyribosomes. Mol Biol Cell 10: 3849-3862.

Stefano JE. 1984. Purified lupus antigen La recognizes an oligouridylate stretch common to the $3^{\prime}$ termini of RNA polymerase III transcripts. Cell 36: 145-154.
Stone MD, Mihalusova M, O'Connor CM, Prathapam R, Collins K, Zhuang X. 2007. Stepwise protein-mediated RNA folding directs assembly of telomerase ribonucleoprotein. Nature 446: 458-461.

Tcherkezian J, Cargnello M, Romeo Y, Huttlin EL, Lavoie G, Gygi SP, Roux PP. 2014. Proteomic analysis of cap-dependent translation identifies LARP1 as a key regulator of 5'TOP mRNA translation. Genes Dev 28: 357-371.

Teplova M, Yuan YR, Phan AT, Malinina L, Ilin S, Teplov A, Patel DJ. 2006. Structural basis for recognition and sequestration of UUU $(\mathrm{OH}) 3^{\prime}$ termini of nascent RNA polymerase III transcripts by La, a rheumatic disease autoantigen. Mol Cell 21: 75-85.

Wang H, Stefanovic B. 2014. Role of LARP6 and nonmuscle myosin in partitioning of collagen mRNAs to the ER membrane. PLoS One 9: e108870.

Wang Z, Glenn H, Brown C, Valavanis C, Liu JX, Seth A, Thomas JE, Karlstrom RO, Schwartz LM. 2009. Regulation of muscle differentiation and survival by Acheron. Mech Dev 126: 700-709.

Weng H, Kim C, Valavanis C, Wang Z, Schwartz LM. 2009. Acheron, an novel LA antigen family member, binds to CASK and forms a complex with Id transcription factors. Cell Mol Biol Lett 14: 273-287.

Wolin SL, Cedervall T. 2002. The La protein. Annu Rev Biochem 71: 375-403.

Yang R, Gaidamakov SA, Xie J, Lee J, Martino L, Kozlov G, Crawford AK, Russo AN, Conte MR, Gehring K, et al. 2011. La-related protein 4 binds poly $(\mathrm{A})$, interacts with the poly(A)-binding protein MLLE domain via a variant PAM2w motif, and can promote mRNA stability. Mol Cell Biol 31: 542-556.

Zanin E, Pacquelet A, Scheckel C, Ciosk R, Gotta M. 2010. LARP-1 promotes oogenesis by repressing fem-3 in the C. elegans germline. J Cell Sci 123: 2717-2724. 

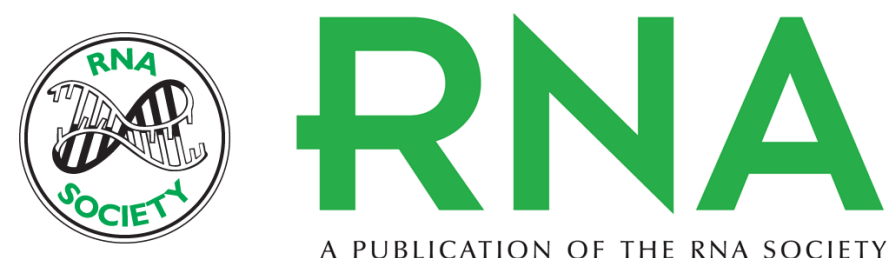

A PUBLICATION OF THE RNA SOCIETY

\section{LARP4B is an AU-rich sequence associated factor that promotes mRNA accumulation and translation}

Maritta Küspert, Yasuhiro Murakawa, Katrin Schäffler, et al.

RNA 2015 21: 1294-1305 originally published online May 22, 2015

Access the most recent version at doi:10.1261/rna.051441.115

\section{Supplemental Material}

References

Creative Commons License

Email Alerting Service
http://rnajournal.cshlp.org/content/suppl/2015/05/06/rna.051441.115.DC1

This article cites 44 articles, 15 of which can be accessed free at: http://rnajournal.cshlp.org/content/21/7/1294.full.html\#ref-list-1

This article is distributed exclusively by the RNA Society for the first 12 months after the full-issue publication date (see http://rnajournal.cshlp.org/site/misc/terms.xhtml). After 12 months, it is available under a Creative Commons License (Attribution-NonCommercial 4.0 International), as described at http://creativecommons.org/licenses/by-nc/4.0/.

Receive free email alerts when new articles cite this article - sign up in the box at the top right corner of the article or click here. 